\title{
Study on the Packing Design of Tourism Product of Intangible Cultural Heritage Based on Hui'an Women's Dress
}

\author{
Xinyan Lu \\ Xiamen Academy of Arts and Design Fuzhou University \\ Xiamen, China 36000
}

\author{
Youjun Tong \\ Xiamen Academy of Arts and Design Fuzhou University \\ Xiamen, China 36000
}

\begin{abstract}
The aim is to design the package which is featured by regional culture, to inherit and develop the intangible cultural heritage of traditional costume culture and design the package of folk tourism products in the perspective of marine culture; The methods contain the choice of the structural model, the pattern, the color and the environmental protection material based on the packaging design of the tourism products with the theme of Hui'an women's garment. Also, the methods include the research of the additional function and value enhancement that aim to transmit the messages of Hui'an women's garment culture in all respects; The conclusion is that with the continuous development of modern tourism and the gradually establishment of "The Belt and Road ", to individuate the packaging design of tourism product by the regional culture is one of the most important ways to inherit the intangible cultural heritage "Hui'an woman garment.
\end{abstract}

Keyword-intangible cultural heritage; Hui'an women's garment; tourism products; packaging design

\section{INTRODUCTION}

Hui'an female costume in Quanzhou, Fujian Province was listed among the first batch of national non-material cultural heritage legacy. With precise structure, distinctive color blending, delicate craft and natural adornment, Hui'an female costume is famous for its strong ocean cultural ambience and unique coastal regional customs. Along with the continuous development of modern tourism industry in Quanzhou region and the rapid advancement of national One Belt One Road construction, it becomes increasingly important to manifest the specialization and differentiation of Haixi tourism industry and relevant tourism product packages. Culture is always credited as the soul of tourism. Therefore, the design originality of tourism product package should take the excavation and refinement of regional culture visual elements as the top priority and accordingly subtly incorporate typical and concentrated visual elements into tourism product package design. As a result, regional feature lies in the most essential feature of tourism products and the essence of tourism product package design to some extent. Package is considered to be an important carrier of cultural information. Successful package works should not only take form, color, texture, material and other design factors into account, but also reflect the cultural connotations of products mobilize the fixed aesthetic taste of customers and create more cultural enjoyment. Traditional Hui'an costume is a special costume culture with most prominent localization, uniqueness and branding traits in southern Fujian region. Together with the rise of traditional costume theme tourism, distinctive tourism product package design related to Hui'an female costume also develops into one of the effective carriers which could inherit and promote regional culture.

\section{The PACKAGE DESIGN ORIENTATION OF OCEAN ENVIRONMENT NATURAL THEME ELEMENT IN HUI'AN FEMALE COSTUMES}

Tourism product usually refers to commemorative article purchased by tourists during the travel. Moreover, tourism product is often labeled as the products with most prominent regional characteristics, for the reason that it not only possesses utility and economic efficiency similar to common souvenirs, but also the peculiarity of folk culture and visual aesthetics. Hui'an traditional fisherwoman costume has intense beauty of decoration and in particular, the silver jewelries, belts and kerchiefs even have more commemorative traits and collection values. The package design of corresponding tourism products also has regional cultural features in Hui'an. As the outwear of products, package design also embodies the cultural connotations of products while transmitting the basic information of products to consumers. [1] As for Hui'an female theme tourism in Hui'an region, tourism brands represented by "Hui'an female customs", "carving technique" and "coastal leisure" are successively released. At the same time, tourism product package design of traditional Hui'an female costumes is also supposed to follow up the development orientation of tourism industry and conform to feature tourism themes. Product package design centering on ocean fishery and other ocean cultures should not only embody natural environment features but also distinctive humanistic feelings as well

Located in the southeastern coastal region of Fujian Province, Hui'an County falls between Quanzhou Bay and Meizhou Bay, adjacent to Taiwan Strait in the east. Credited as "The Home of Coast", "The Home of Carving", "The Home of Construction" and "The Home of Fishery", Hui'an County has distinctive peninsula geographical features and 
ocean fishery production features. Chongwu ancient city, Qingshan Bay, Xisha Bay and many other similar natural coastal scenic spots and human landscapes have become symbolic tourism areas in Hui'an. A large group of tourism brands in Hui' an represented by "Charming Folk Custom County in China- Chongwu", "The Eight Most Beautiful Chongwu Coastlines in China", and "The Most Beautiful Village in Fujian" enjoys the fame in overseas countries. These coastline natural landscape and busy Hui'an females bring out the best in each other and embody the harmony between human and nature. In terms of the tourism product package themed with Hui' an female costume, the coastal natural elements could be transformed into symbolic signs after elaborate refinement. By making full use of the natural landscape including the blue ocean and golden beach and the subtle application of natural figures, these signs could realize the high generalization of invisibility by representing visible objective facts. Various forms of ocean creatures also consist in one of the main package design themes. The colors and forms of all kinds of fish and shellfish could give designers infinite inspirations. The package design originating from the nature well indicates the worship for ecological civilization and meanwhile guides the green consumption consciousness and environmental protection consciousness of consumers, thus manifesting the harmonious relationship between man and nature. [2]

\section{The PaCKAge Design ORIENTATION OF UNIQUE HUMANISTIC FOLK-CUSTOM ELEMENT IN HUI'AN FEMALE COSTUMES}

Humanistic folk-custom elements with regional features prove to be the most prominent representation of nonmaterial aspect in product package. The features of Hui'an female costumes could be summarized by a classical ballad "the feudalistic head but the democratic stomach -saving the coat but wasting the pants". "The feudalistic head" refers to the headwear of Hui'an females - namely the colorful kerchief and yellow bamboo hat. Since females have to cover their face with the kerchief and wear a round bamboo hat on the head, they only show half a face, which is named as the "feudalistic head". "Saving the coat" means that the upper outer of Hui' an females is rather short just above their waist and the cuff is contracted up to the middle forearm. It drives from the thrift of clothing materials. "The democratic stomach" means that the tight and short upper outer of females would not conceal the navel of females at labor, which fully indicates the tradition of democracy. "Wasting the pants" means the sharp contrast between loose and large bottoms and tight and short upper outer. Among others, the most interesting feature of Hui'an females should be their hairstyle, ranging from the big head bun-shaped hairstyle since marriage to ocular head-shaped hairstyle and round head-shaped hairstyle when growing older. Exactly after the liberation, Hui'an females started to wear colorful kerchief and yellow bamboo hat. The hairstyle and headwear in each stage represent the evolution of folk customs in different period. Hui'an female costume theme tourism product package design should start from the understanding about Hui'an female costume culture and the finding of genetic control factors in cultural composition. In the meanwhile, the analysis of cultural structure actually means dividing culture into mutually-dependent and mutually interactive material culture, institutional culture and spiritual culture. [3] As the non-material cultural heritage, Hui'an female traditional costumes and tourism product package figure, content and pattern could reflect the folk-customs of Hui'an females, regional culture of southern Fujian and regional aesthetic and cultural functions of Hui'an feature tourism product package. The package design could deliver cultural information from multiple aspects while the culture could simultaneously direct the orientation of package design. After all, culture should always be taken as the key of package design. [4]

\section{The Package Design of Hui'an Female Costume THEME TOURISM PRODUCTS}

With regard to the design theme of series package cultural attributes, its multifunctional features have attracted the attention from more and more designers under the package design process in new era. [5] The package design of Hui'an female theme is inseparable from the image of Hui'an females in basic style design, graphic element and visual texture expression. As the image symbol of Hui'an females, costumes' package design should highlight tradition and local features and main visual elements such as outlook, color and figure should be successively designed with image elements, decoration elements, color elements and connotation elements so as to embody the local features and ocean cultural features in Hui'an region. Confronted by tourists at home and abroad, traditional Hui'an female costume tourism products should take aesthetic and selling functions into account and meanwhile concentrate on the traditional cultural spirits and implications of Hui'an females characterized by simplicity and hard-working quality during package design process. This implies that the structure, color, figure, letter symbol, texture, material and craft of costumes should deliver the optimal information and judgment to tourists. Larger rectangle carton should be the prioritized package. Meanwhile, little cube and cylinder carton are the main containers of accessories. Those cartons could present different visual senses after incision and hollowing processing - the cube means "strictness and severity" while the round means "simplicity and perfectness." Elaborately hand-made cloth bag with embroider might be a creative package form. To be sure, little accessory package box could be shaped like ocean creatures, local architectures or statues so as to obtain better promotion results. This is because that such package could satisfy the basic functions of accessory package and meanwhile grasp consumers' psychological consumption needs for the coastal culture in Hui'an region.

\section{A. The Application of National Feature Figures and Colors}

Package design with national features has dual implications, namely formal nationalization and connotative nationalization. The former refers to the design of package figure, color, character font, material and other design styles based on tradition and nation. The latter refers to the expression of national cultural deposits and ideological realm based on national spirits and connotations in design works. [6] The coordinate matching between color and figure of 
tourism product package could directly elevate the taste and value of products. Traditional emblazonry has wide application in modern tourism product package design. Either the shading or the main figure and corner adornment could impress people with a sense of simplicity and freshness, nostalgia and adornment. As for the pattern of Hui'an female costumes, Hui'an females in different regions all prefer geometry pattern, flower and bird pattern. In terms of themes, female costumes are filled with ocean cultural ambience, which could be seen from the pleasing marine sea creatures, human stories and the beacon of fishermentriumphal arch. Plain and common themes in daily life consist of the creation inspiration source of Hui'an female costumes. Artistry originates from life but more importantly the feelings about life. Hui'an female costume patterns will select, arrange and configure the visual element materials and turn them into the desired package compositions so as to build "Hui'an female image". By studying and excavating Hui'an female costume figures and adding modern design concepts in local tourism product package design, designers could make people appreciate the beautiful scenes and meanwhile promote both patterns and culture. [7] Traditional figure patterns with intense ethic group spiritual features and strong vitality could reveal the diligence and simplicity of Hui' an people and their pursuit for beautiful life. Admittedly, those patterns also express the authentic blessings of Hui'an people for tourists.

Hui'an female costumes mainly take blue and black as the main color while red and yellow as the matching color. The costumes made in Chongwu and Shanxia regions prefer black and blue. Their pants usually choose black as the background color and match with red, yellow, green and purple. In contrast, females in Xiaozuo and Jingfeng prefer costumes dyed with green and blue, yellow and red accessories and kerchiefs with diversified colors and figures. Traditional Hui'an female costume tourism products could use yellow and red, or red and blue or red and black as the main colors. Moreover, all the other decorative colors should conform to the theme of products and highlight the color culture of Hui'an region.

\section{B. Function Expansion}

Package design of Hui'an female costume tourism products should emphasize personality and themes. Once the overall package is imbued with national elements and Hui'an elements, the object and traditional Hui'an costumes with strong aesthetics could bring out the best in each other and reach the optimal aesthetic outcomes. In the first place, the package design of Hui' an female costume tourism products should be certain artistic works and crafts. In addition, either box form or bag form is expected to represent Hui'an local culture and spirits. To sum up, designers should try to put aesthetic design above commercial utility and condense local culture to promote humanistic spirits. In this way, consumers who have bought such costumes and accessories could even put the package as indoor decoration ornaments or even greeting gifts. Tourism product package design is also an important medium and carrier of local tourism culture promotion and transmission, which urgently requires the subtle application of regional features. How to represent such local features requires designers to stand from the point of local culture. Making visual innovation of tourism product package is the responsibility and liability of design. In most cases, tourism products would be taken as personal souvenirs, collections or presents to relatives and friends. A good tourism product should urge people to memory or yearn for the scenic spot by product itself and high-quality package design. Therefore, in addition to the considerations for style, texture, color, craft, accessory quality and value, the package of Hui'an female costumes itself should become one product or a work of art with unique functions different from common tourism costume packages.

The commercialization package design of Hui'an female costume tourism products is reasonable to persist in the people-oriented ideas forever. In terms of the function, package design should stick to the convenient portability principle in combination with consumers' purchasing requirements and develop in the direction of exquisiteness. Moreover, the functions have to be humanized while the names of package boxes have to be understandable, accessible and readable. The printing of package has to be as precise as possible, without any destruction of fisherwoman ambience and humanistic attributes. Convenience package is advised to use fabric bag while high-end package boxes. At the same time, it is better to issue composite design and suit design package boxes or bags for costumes, kerchief and accessories. Besides the small volume, such package had better adopt light materials. In order to create a faint fragrance sense after opening the costume or accessory boxes, drying agents might be helpful in erasing abnormal flavor.

\section{The Package Design of Sustainable ENVIRONMENTAL PROTECTION}

Sustainable development principle has intimate correlation with package design. In the field of package design, the application of sustainable concepts obtains more and more attention. Moreover, modern package design focuses on environmental protection, greenization and original ecology. The package design of green and lowcarbon tourism products not only has competitive advantages, but also conforms to the strategic requirements of sustainable development. At present, the international society universally follows $5 \mathrm{R}$ principles, namely material reduction, reuse, recycle, recover and reservation [8]. Hui'an female costume tourism product package should also pay attention to the low-carbon attributes of package materials and crafts, including simple structure, environmental-friendly material, distinctive embroider pattern and national styles, portability, reuse as well as commemorate functions. On the other hand, the designers are supposed to decrease the processing crafts which might influence the environmental-protection abilities and reuse rate of materials such as membranae tectoria, gilding, silver plating and binding. In the end, the package design should place emphasis on the application of natural materials, the combination of natural and simple styles and harmonious aesthetic feelings. 


\section{CONCLUSION}

National and regional culture laid the foundation and theme basis of tourism product package design in all times. Different regions cultivate different nationalities while different nationalities generate different cultures. Package design in modern times incorporates the essence of national culture and regional culture and tries to find the coherence point between traditional culture and modern culture, for the view of better promoting national and regional culture. [9] Themed with non-material cultural heritage - Hui'an female costume elements, relevant tourism product package endows the structure, material, color and pattern of package with both old and novel cultural implications. The innovation of Hui'an female package design has important meaning for the promotion of Hui' an female costumes' non-material cultural heritage, regional economic growth and urban feature publicity, consumption stimulation and cultural inheritance. [10]

\section{ACKNOWLEDGEMENT}

The authors wish to acknowledge the national social science foundation of China (15BG104) for the financial support.

\section{REFERENCES}

[1] Li Yan, Xiong,Jin-hui.Hakka Tourism Product Packaging Design Ideas to Explore[J].Packaging Engineering,2009, 12:220-221.

[2] Dai Dandan.The Application of the Analysis of Natural Elements in Packaging Design[J].zhuangshi. 2010,02:135-136.

[3] Wang Wenquan.The Reconsideration of Modern Packaging Design and Humanistic Thought. Journal of Guangxi University for Nationalities (Philosophy and Social Science Edition), 2005(12):282283.

[4] Zhao Xi, Yan Pin,Gao Haiyan,Packaging Design Research Factors of Sustainable Development[J]. Journal of Chongqing University. 2011(2):136-141.

[5] Song Donghui.Wu Tianyu. The Innovative Research and Production of Multi-Functional Packaging Structure[J]. Hundred Schools in Arts, 2013(7):177-179.

[6] Li Yi.National Characteristics in Packaging Design Innovation[J]. Packaging Engineering, 2008(09): 187.

[7] Yan Qinfang, Jiang Qui. The value of design in the packaging design of minorities in guizhou[J].Guizhou Ethnic Studies2013(1): 61-63.

[8] Yang Guang, Er Yupin.Packaging Design of Low Carbon Era[J]. Packaging Engineering, 2011(02): 82-83.

[9] Wang Rui. National Regional Culture's Influence on the Modern Packaging Design [J]. National Art, 2010(3): 102-107.

[10] Jiang Zaixin,Wang Lin-lin.The Mongolian traditional culture elements in packaging design [J]. Guizhou Ethnic Studies, 2013(2): 82-84. 